\title{
On the Transformation of Government Functions in the Construction of Urban Community Culture in the Northwest Minority Areas----A Case Study of Da wu kou District, Shi zui shan City, Ningxia
}

\author{
Yang $\mathrm{CHEN}^{1, a_{\star}}$, Jing $\mathrm{HAN}^{1, b}$ \\ ${ }^{1}$ Institute of Management, Southwest University for Nationalities, Chengdu, Sichuan, China \\ a768453797@qq.com, b365977270@qq.com \\ *Corresponding author
}

Keywords: Community Culture, Governmental functions, Culture construction.

\begin{abstract}
The sustainable and healthy development of the construction of community culture in minority areas is based on the accurate positioning of government functions, which cannot be separated from certain government functions and behaviors. This article takes the community culture construction in the northwest minority area as the breakthrough point, and takes the government cultural function as the research object, In combination with the reality of construction of community culture in Dawukou District, Shizuishan City, Ningxia, Analysis of urban community culture construction in national regions of the necessity of the transformation of government functions and the necessity and feasibility of the strategy.

The construction of urban community culture is initiated by the Chinese government in 1990s. It is a systematic project to construct the urban community culture with modern meaning and regional characteristics. Its essence lies in the basic elements of the modern community culture, such as the government led initiative to create activities, foster community awareness of urban residents, community cohesion and so on. The role of Chinese government in the construction of urban community culture is directly related to the sustainable and healthy development of urban community culture construction, and the government's function is determined by the government's responsibility and function.
\end{abstract}

\section{An Overview of the Construction of Urban Community Culture in the Northwest Mino rity Areas}

"Community culture" was first proposed by the American scholar Do Mason. General is gradually formed in the long-term community life and social communication of the residents living in a particular region of similar value concept, behavior patterns, traditional customs and group consciousness. It is embodied in the form of the visible community environment, order, the style of the residents, the way of life, and also includes the group awareness, values and ideals in the community residents' behavior culture.

All kinds of big cities and small towns in ethnic minority areas in Northwest China, as, gathering in urban residents of China's ethnic minorities, the community culture is the concentrated reflection of northwest ethnic groups at the community level. In recent years, in the urbanization and the process of modernization of government in ethnic minority areas in Northwest focusing on the role of its economic functions. Urbanization, community construction is in the ascendant, community culture construction belongs to new things.

Dawukou district is located in northern Ningxia, belonging to the Ningxia autonomous region of Shizuishan City. In the process of economic and social development, city community culture construction is still in its infancy, there are many problems. Such as: community cultural facilities construction is not balanced, the residents of the community lack of culture independent consciousness, government leading mode and disjointed cultural needs of residents, community cultural backbone of the urgent need to strengthen the construction and so on. Dawukou district government should further strengthen the functions of public cultural construction, firmly establish the "people's livelihood and cultural consciousness. 
The Necessity of Government Function Transformation in the Construction of Commun ity Culture in Northwest Minority Areas

\section{The Role Played by the Government in Fulfilling the Functions of Community Cultural Construction}

\section{The Guide to the Construction of Community Culture}

In the city community governance in our country, although the government from the "centralization of power" to "decentralization", but overall, the autonomous organization of community development is not mature, can not completely replace the function of the government. In practice the process of community culture construction in Dawukou District, the government's guiding position for the following aspects: first, the government has played the cultural construction of related laws and regulations. The role of the local government should change according to the development of city community construction in ethnic minority areas in Northwest China, the transformation of functions and constantly improve the relevant laws and regulations on the construction of community culture, to ensure the promotion of the implementation of laws and regulations. Secondly, the macro guidance of community construction and development from the culture. The overall goal of the government's macro planning community culture construction, do a good job in different regions between different communities unified coordination and local development strategy. To develop a scientific, reasonable long-term goals and short-term objectives of the unity of the feasibility of target system.

\section{The Financing and Resource Allocation of Community Culture Construction}

The northwest multi-national area city community cultural development is still in the primary stage, the self hematopoietic function of community ownership of the economy is not strong, so funding basic by government investment and financing. Rely on social forces to do the construction of community culture consciousness weak, mechanism is not perfect. The government's commitment to human, material resources, financial resources of the main configuration function.

\section{The Guide of Core Values in the Construction of Community Culture}

The community is an important cell of society, city community is an important basis to cultivate and practice the core values. The community construction has become an important position is the practice of socialist core values to implement the specific requirements of Scientific Outlook on Development, is a key subject in the unified value consciousness. Dawukou District People's Government people-oriented in the construction of community culture, improve. The sense of participation of community residents. In combination with the actual situation, carry out various activities to create entertaining, diverse forms of civilization, and continuously enrich the connotation of core values activities.

\section{Problems Existing in the Government Functions in the Construction of Community Culture in the Northwest Minority Areas}

First of all, by the local political and economic development lag constraints, there is a government function distribution is unreasonable, blindly strengthen economic functions, social and cultural development functions to perform not in place, community cultural construction investment less. Secondly, subject to government supervision and management system is not perfect, performed in cultural functions exist a lot of absence, dislocation, offside phenomenon, which restricts the development of community culture construction. Finally, due to the northwest ethnic region history, culture and education development level is relatively backward, personnel quality relatively low, functional departments of the government staff function level does not reach the designated position. Superiors in the presence of function of planning is not in place, function guidance is not in place and so on. Basic level civil servants do not have enough sense of service in performing their functions. 


\section{Measures}

\section{Implement People-Oriented Concept, Strengthen the Status of Residents}

In community culture construction in the process, the government should overcome the deviation of understanding, safeguard the people's democratic rights. The initiative to mobilize residents, improve the sense of participation, to provide personalized meet the service needs of the residents. To ensure that the community residents to participate in community culture construction of decision, organization, implementation, management and supervision of the whole process of. Coordination of government functional departments and the community inhabitant autonomy, improve the public opinion basis for government decision-making. Important decisions about the community culture construction should strengthen residents' communication, conducted polls. To carry out the diversified, multi-level community cultural activities, to ensure that residents in all ages.

\section{Change the Function of the Output, to Achieve Cooperation and Build Community Culture}

Make full use of social resources and the realization of the community culture of cooperation to build. A change of government the past directly involved in for indirect guidance, to the neighborhood more autonomy. Clear the functions and responsibilities of the neighborhood and street..Actively guide the relationship between community culture construction and other industries, expand more places for community sports activities. Financing aspects in guarantee of government financial input at the same time, and actively expand the social donation channel, guide the enterprises and institutions, social organizations and residents of the capital contributions.

\section{Integration of Human Resources, Improve the Quality of Staff}

In the low developing level of education and culture of northwest minority areas, how to cultivate talent, the introduction of talent, retain talent is the basis and premise of cultural construction work. First of all, in the introduction of talent, broaden the introduction of talent channels, open recruitment, to ensure that the inflow of high-quality personnel, to optimize the knowledge structure of community cultural construction workers. Secondly, pay attention to the training and education of staff, strengthen the service consciousness, to improve their overall quality. Finally, to mobilize the initiative and enthusiasm of the community workers. To increase the salary treatment, improve the working environment. To establish a continuous and effective incentive mechanism, the effective combination of material and spiritual incentives.

\section{Respect for Community Differences, Avoid "One Size Fits All"}

First of all, in the eastern part of the experience of the development of urban community culture construction, we cannot ignore the fact that the difference between the East and the west is an objective fact. Combined with the local history and culture as well as religious beliefs, and constantly adjust the community cultural strategy.

Secondly, the construction of community culture in a city, also want to consider the differences between different communities, make full use of cultural resources, overall planning according to the actual needs. Finally, different levels in the same community, residents of different interests have different cultural needs. Should carry out multi-level diversification, preferred by residents of the community cultural activities to meet the diverse needs

\section{Conclusion}

Community culture construction is the soul of the community construction, one of the important content of culture construction is a, for the construction of a harmonious society, enhance ownership of community residents has a very important significance. Transform the function of government in the construction of community culture, improve the level of community culture construction, for Ethnic Regions of the northwest Mandarin construction is of great significance. 


\section{Acknowledgement}

This research was financially supported by postgraduates' innovative research projects of Southwest University for nationalities. (CX2016SZ005)

\section{References}

[1] Yuan De. Community culture theory [M]. Chinese Society Press, 2010

[2] Sun Li. Study on community culture construction of Tianjin Peace District [J]. Department of management economics, Tianjin University, 2010

[3] Zhang Hua. The problems and Countermeasures of the construction of community culture in the context of harmonious society [J]. border economy and culture, 2011

[4] Cao Yiping. The revelation of urban community culture construction in developed countries and regions [J]. Journal of Shenyang University, 2011

[5] Zhou Chang. The construction of ecological civilization in our country government function and responsibility of the [J]. Northeast Normal University, in May 2012. 